Emilia Woźniczko

University of Silesia in Katowice (Poland)

\title{
International Politics and the Chinese Reforms
}

\author{
Book Review: Peng Sen, Zhang Xiaochong \& Jin Chuntian, Reformujac Chiny. \\ Uwarunkowania międzynarodowe. Toruń: Wydawnictwo Adam Marszałek \\ Publishing House 2015 (pp. 495). ISBN 978-83-8019-254-6.
}

China has fascinated diplomats, traders and travelers for centuries. In the reviewed book, the authors try to present how China changed into a country where everything has to be the biggest or the best. They discuss how should the complicated system of reforms work. They presented the reader insiders' observations, assumptions and possible future developments of the Chinese order. As a result the book is a lecture on historical trends in a comparative context.

The book includes a preface and seven chapters on the different aspects of Chinese reforms - their background, reforming the economy, entrepreneurship, social system, labour law, agriculture and governance, as well as the general macroeconomics of China. The last chapter discusses the adverse outcomes of new politics, and countermeasures adopted by policy-makers.

The authors describe the Chinese way of reforms referring to developed literature on country's history and politics. They state that "reforms in China in the second half of the $20^{\text {th }}$ Century are the largest social experiment in the humankind history. (...). The reforms are a reflection of the historical inevitability of events. From the very beginning, the reforms have encountered a difficult situation in politics, economy or other fields" (Pang, Zhang \& Jin, 2015, p. 8).

The term 'social experiment' raises many doubts, so one must ask oneself whether it is relevant in the context of the subject matter. However, from the context of the publication it appears that the reform on such a scale and so thoroughly conducted, according to the authors, was not practiced in any country in the world. China has introduced a kind of a novelty to the international arena. 
The volume of work is impressive, and the outlined subject matter refers to the intentions of the authors. Strictly defined aspects have been thoroughly analyzed. The reader does not feel that the volume of publication negatively affects its reception. Even a person who has not dealt with a professional economic nomenclature will be able to some extent understands and assimilate the principles and ways of carrying out such complex reforms.

The authors have been exhaustive in describing the issue of China's economic reform, and have also highlighted its multiplicity, also referring to the improvements of other states, such as the Union of Soviet Socialist Republics, Yugoslav countries, or Poland. The reformers described these reforms as follows: "In the face of the shortcomings of the planned system and the shortcomings of the existing economic model, the Soviet Union and the countries of Eastern Europe have attempted to introduce reforms. [...] in the 1980s, the continual search for a path of change was taking place in Europe. However, due to the rigidity of the theory and ideological barriers, the radical evaluation stage of socialist development $[\ldots]$ these reforms was interrupted in the middle or carried out in unsuitable areas (Sen, Xiaochong \& Chuntian, 2015, p. 27). The term 'attempt' at this point is crucial, because it could not be any of the launched reforms. To bring about the end without a change in the state system, which took place only later, and at that time in China, the improvement was implemented successfully.

To the disadvantage of this monograph, there is a small amount of specialist literature by which reforms have been discussed in other countries and compared to the changes in China. When considering the problems of modification, there were no references to adequate literature. The magnitude of the authors' knowledge is not denied, but the comparison to other countries, it must be based on scientific monographs - not one, but much more, for a complete picture of the changes in a given state. It is only after a thorough analysis of the material that we have to deal with the comparison - in this case, the economies or reforms - with the steps taken in China.

For example, the reforms in Poland and other European countries have only been hinted at, referring to only one author, the meaning of the improvement of the regime at the time, and the reforms were described as if the author had learned from the second hand, without the scientific basis of conclusions. "In Poland, the Polish road Gomulka was carried out by less than three years, and then was withdrawn under pressure from the country and abroad. Poland has returned to the old road, focusing again on the development of heavy industry And by making it 60 years ago, citizens had to live very modestly in the name of socialist industrialization. Policy successor Gomulka, Gierek, which consists of reaching a large momentum, high accumulation and high consumption, aimed at promoting economic growth, by opening the country to the outside, but achieved the opposite effect" (Sen, Xiaochong \& Chuntian, 2015, p. 28).

When discussing such important issues, one should be well prepared, have adequate knowledge and scientific workshop, or consult experts to avoid errors during the analysis. It can be a dangerous impression that reforms in Poland as well as in other countries have 
been presented to reduce their value, while the Chinese reforms have been presented in the best light against the background of the international arena.

In this monograph, there is a negligible amount of scientific footnotes and adequate references to literature. There is an impression that the authors have used only and exclusively their own knowledge, while the literature was rather ignored. The book that is so rich in information should be referred to other authors, government documents or even scientific or press articles. In such a delicate and complex subject matter, one should not rely only on one's knowledge or a small number of references in the bibliography.

For example, the Report of the Sixteenth Communist Party of China's Communist Party - there is no reference to it in footnotes, there is no information on where this document is located and where it can be found. The authors, on the other hand, seem to know perfectly well what this document contains: "The report also contained concrete, targeted steps to build a moderately affluent society. [...] The report made as substantial ongoing evaluation of twenty years of an important period of strategic opportunities when it was built a moderately prosperous society" (Sen, Xiaochong \& Chuntian, 2015, p. 77). The steps were hinted, but the details were not given to the reader. It is also worth noting that the numerous repetitions contained in the cited paragraph and the wrong sentence structure impede the correct reception of the publication.

The linguistic issues of this monograph also leave much to be desired. Problematic in reception is to describe the events from the perspective of the Chinese: "By engaging in the construction of the economy, we had to face the fearful, devastated, broken residue of the former China. On the way we made some mistakes and we came across complications. However, when we experienced these mistakes and failures, we gradually began to deepen our knowledge and understanding of the prevailing conditions in China and gradually we stepped on the right path leading to wins" (Sen, Xiaochong \& Chuntian, 2015, p. 32-33).

This monograph was considered scientific, but it is unacceptable to make such a remark as the one cited above. In scientific monographs authors have no right to allow themselves for such a personal confession and the excessive pathetic statement like the one above seems to be superfluous and inadequate to the language of scientific monograph. Authors in many places in the book have allowed themselves for such exaggerated pathetic and lead a kind of 'stories' from a Chinese perspective. From this point, one has to wonder whether this peer-reviewed publication should be considered as a valuable scientific book, from which one can gain knowledge and information, or for a reportage or a popular science-fiction project with no substantive background.

The following statement is puzzling: "But as long as we were self-confident, we realistically analyzed the causes of problems in the practice of socialism in the Soviet Union and Eastern Europe, we used the lessons of the Soviet Union and Eastern Europe and we constantly promoted theoretical, scientific, institutional and technological innovation, we were able to change the crisis into an opportunity" (Sen, Xiaochong \& Chuntian, 2015, p. 51). From the linguistic point of view, it is not known from what angle it should be interpreted. 
Does the subject we refer to the perspective of the authors of the publication or to the entire Chinese nation? Once again we are dealing with excessive patriotism which fits the reception of the serious subject matter of the reviewed book and even makes it a bit comic. The unnecessary use of catechism combined with a recession or the experience of other states spoils the reception of the publication.

From the perspective of the reviewer or reader, it is important to realize, however, that this publication was originally written in Chinese, then translated into English, and then into Polish. On the one hand, the task of an interpreter is not to guess what the author of a given publication has in mind, and therefore some language deficiencies may arise, but on the other hand, grammatical correctness is everywhere. This issue is quite problematic when it comes to books translated from a foreign language.

The way of publishing this book is adequate to its content - a traditional format that is practiced in publications, with an eye-pleasing font size that is well read with additional advantages. The volume of the book has been adjusted to its contents.

Review frameworks do not allow for more citations to be shared with its readers or a more detailed commentary on the subject matter by topic authors. As a reviewer, I recommend everyone this fascinating reading, despite the fact that it contains some shortcomings that impede reception and understanding of the content in question. As a reviewer, I think it is a book worth reading and I would recommend it not only to devotees of the subject of reform in China. It helps to understand the specific issues that occur in this country, but also to discover a secret from the reader - the mystery of the complex mechanisms that take place in China.

\section{References}

Peng Sen, Zhang Xiaochong, \& Jin Chuntian (2015). Reformujac Chiny. Uwarunkowania międzynarodowe. Toruń: Wydawnictwo Adam Marszałek.

\section{Author}

\section{Emilia Woźniczko}

University of Silesia, Institute of Political Science and Journalism.

Contact details: ul. Kilińskiego 36e, m. 5, 44-200 Rybnik, Poland; e-mail: emi.wozi@gmail.com 